\title{
The value of autonomy in medical ethics
}

\author{
Jukka Varelius ${ }^{1,2}$ \\ ${ }^{1}$ Centre for Professional Ethics, University of Central Lancashire, Preston PR1 2HE UK; ${ }^{2}$ Emmauksenkatu 5 A 7, 20380 \\ Turku Finland (phone: +44-0-1772-892546; fax: +44-0-1772-892942; e-mail: varelius@hotmail.com)
}

\begin{abstract}
This articles assesses the arguments that bioethicists have presented for the view that patients' autonomy has value over and beyond its instrumental value in promoting the patients' wellbeing. It argues that this view should be rejected and concludes that patients' autonomy should be taken to have only instrumental value in medicine.
\end{abstract}

Key words: autonomy, instrumental value, intrinsic value, patient, wellbeing

\section{Introduction}

Autonomy is a central value in Western medicine and medical ethics, but exactly what kind of role medicine ought to give to patients' autonomy seems to be somewhat obscure. It is plausible that autonomous persons are often in the best position to determine what would be good and bad for them (see, e.g., Sumner (1996)) and, consequently, it is arguable that there is good reason to consider patients' autonomy to have instrumental value in medicine. But in addition to giving patients' autonomy instrumental value, some bioethicists maintain that autonomy is so important that there are cases where patients should be allowed to make their own choices about their treatment even if it is clear for all parties involved that others would be in a better position to make choices that would serve the patients' wellbeing (see Glover, 1977, pp. 80-81; Buchanan and Brock, 1990, pp. 38-39; Beauchamp and Childress, 2001, pp. 176-187; ${ }^{1}$ Gillon, 2003, p. 310; Harris, 2003, p. 11). Some of these philosophers maintain that patients' autonomy can be restricted if there is a threat of very severe harm to patients' wellbeing, ${ }^{2}$ but others seem to accept no limits to patients' autonomy when there is no danger of harming others. ${ }^{3}$ In this article, I will assess the reasons bioethicists have presented to support the view that the value of patients' autonomy is not exhausted by its instrumental value in promoting patients' wellbeing.

\section{The notion of autonomy}

Although the notion of autonomy has been used in many distinct senses in different connections, in biomedical ethics there is a common core understanding of the meaning of this notion. According to this idea, autonomy means self-government. Of course, what exactly this means is controversial. The proponents of the view that patients' autonomy has value over and beyond its instrumental value in enhancing patients' wellbeing mentioned above accept a procedural conception of individual autonomy (see Glover, 1977; Buchanan and Brock, 1990; Beauchamp and Childress, 2001; Gillon, 2003; Harris, 2003). Beauchamp and Childress (2001, p. 58), for example, write as follows:

Personal autonomy is, at minimum, self-rule that is free from both controlling interference by others and from limitations, such as inadequate understanding, that prevent meaningful choice. The autonomous individual acts freely in accordance with a self-chosen plan, analogous to the way an independent government manages its territories and sets its policies. A person of diminished autonomy, by contrast, is in some respect controlled by others or incapable of deliberating or acting on the basis of his or her desires and plans. For example, prisoners and mentally retarded individuals often have diminished autonomy.

According to this kind of conception, a person's beliefs, desires, choices, decisions, etc. are 
autonomous when they fulfil certain procedural criteria. As the above quotation suggests, there can be different views about exactly how these criteria should be formulated. I would however argue that all plausible procedural theories of individual autonomy accept at least the following requirements. If a person's behavior results from such things as compulsion and weakness of will, then it is not autonomous but heteronomous. If a person's choices, decisions, beliefs, desires, etc. are due to such external influences as unreflected socialization, manipulation, coercion, etc., they are not autonomous. And if a person's beliefs concerning some matter are false, inconsistent with each other, or she is uninformed about that matter without her realizing this, then she is not autonomous with respect that matter. According to this kind of conception of individual autonomy, an autonomous person may thus have false beliefs and beliefs that are inconsistent with each other and she may be uninformed about some matter as long as she realizes it; in her self-regarding matters an autonomous person may choose not to know certain things, she may want to take risks, or she may consider a decision she is to make too inconsequential for information gathering.

In addition to those mentioned above, a further characteristic of individual autonomy relevant to the following discussion is that autonomy admits of degrees. There is thus a continuum of autonomy, and different individuals at different phases and with respect to different circumstances of their lives occupy different locations on that continuum. It is usually accepted that persons need not be ideally autonomous in order to qualify as autonomous agents. Instead, it is taken that, for practical purposes it is possible to determine thresholds, and that those whose autonomy exceeds the relevant threshold qualify as autonomous persons. ${ }^{4}$

The procedural conception of autonomy contrasts with theories of autonomy which maintain that an autonomous person will always act on the basis of certain motives and/or will accept certain substantive views. ${ }^{5}$ Kantian conceptions of autonomy, for example, usually ${ }^{6}$ hold that in their decisions and actions autonomous persons do not give weight to the particular desires and wishes that they have. Instead, autonomous persons are individuals whose actions are determined by impartial and abstract principles of reason. Concerning the case of a suffering patient who requests for euthanasia to end her distress, for example, Kantian conceptions of autonomy would imply that there is no morally compelling reason to accede to the patient's wish as it is based on her personal attitudes towards pain and death, not on a maxim that is universalizable in the Kantian sense. The most important difference between these kinds of conceptions of autonomy and the procedural theories of autonomy is that, as such, the latter do not determine answers to such questions as whether or not voluntary euthanasia is morally permissible, but allow for different possibilities. If, for example, the patient's wish to die fulfils the criteria that a procedural theory of autonomy presents for autonomous desires and wishes, and other things are being equal, then the theory implies that the wish should be obeyed. It is not possible to go into to the pros and cons of different kinds of conception of the nature of autonomy here. ${ }^{7}$ As the procedural conception of autonomy is commonly accepted in medical ethics, ${ }^{8}$ below I will concentrate on the value of autonomy perceived in that way.

\section{The notion of intrinsic value}

Below I will refer to the view that the value of patients' autonomy is not exhausted by its instrumental value in promoting their wellbeing as the view that patients' autonomy has intrinsic value. In philosophical literature, the notion of intrinsic value has been used in different senses, and philosophers disagree over what, if anything, has intrinsic value, and over whether or not there can be a coherent concept of intrinsic value at all (see, e.g., Zimmerman, 2001). To use the expressions commonly used in characterizing intrinsic value, the intrinsic value of autonomy can be described as the value that autonomy has in itself or for its own sake, as opposed to its being valuable for the sake of something else. The distinction between something's being valuable for its own sake and something's being valuable for the sake of some other thing is perhaps easiest to grasp by way of illustration. Consider the case where A asks B whether it is good that a physician treats B's broken leg and B answers, "Yes, of course it is." A then goes on to ask why the physician's acting in this way is good, and B replies that it is good because it is good for her that both of her legs work properly. A continues by inquiring why it is good for B that both of her legs work normally, and B replies that it is good for her because otherwise she could not go on with her life in the way that she wants. Then A wants to now why is it good for B to be able to continue living her life in the way that 
she likes, and B replies, for example, that it is good for her because it brings her pleasure. But then A wants to know what is good about pleasure. At that point B could just state that pleasure is good, or she could try to present reasons for why pleasure is good. In any case, at some point B would have to put an end to the questions, because she would recognize that if one thing derives its goodness from some other thing, which in its turn derives its goodness from yet a third thing, and so on, there would come a point at which B reaches something whose goodness is not derivative in this way, something that just is good for its own sake, or intrinsically good. Those who maintain that there ultimately is nothing of intrinsic value or that the notion of intrinsic value itself is incoherent could of course argue that such a point never comes. Instead of going into this controversy, I will for the sake of argument assume that there comes a point at which the goodness of a thing is not derived from the goodness of some other thing and that autonomy is at least a plausible candidate for a thing having this kind of value. ${ }^{9}$ With this understanding of the view that autonomy's value for patients is not exhausted by its instrumental value in promoting their wellbeing, I turn to assessing the arguments that bioethicists have presented to support this view. A problem with assessing the arguments for the view that patients' autonomy has intrinsic value is that it is often hard to say exactly what these arguments are. The proponents of this view usually present only some brief remarks to support it; they do not provide detailed characterizations of exactly how they perceive the value of autonomy ${ }^{10}$ nor specific explanations of how these remarks are supposed to show that autonomy has value independently of its value in promoting wellbeing. In fact, only two arguments for the view that patients' autonomy has intrinsic value can be extracted from the bioethics literature. ${ }^{11}$ Below I will consider each of these two arguments in turn. I will begin with what would seem to be a somewhat less important argument and then turn to the main argument for the view that autonomy has intrinsic value for patients. $^{12}$

\section{The Brave New World}

Defenses of the view that autonomy has intrinsic value sometimes refer to cases where persons are, in the manner of the people in the society of Aldous Huxley's novel The Brave New World, made completely happy by manipulating their attitudes so that, contrarily to what really is the case and what they really would want, they believe that they are living just the kind of life that they want to live (see, e.g., Glover, 1977, p. 81). ${ }^{13}$ It is suggested that we would not want to become like these persons even if we could thereby become perfectly happy and that this demonstrates that we put intrinsic value on our autonomy. However, if a person is to believe that she is living just the kind of life that she wants to live when in actual fact her life is quite different, all knowledge that her beliefs concerning her life are artificially produced must be erased from her head. In other words, the person's self, if it is legitimate to speak of a self in the case of these kind of persons, must be as artificial a product as her belief that she is living the kind of life that she wants to live is. And it is intuitively plausible to accept that a person with this kind of self would not really be a person at all anymore (cf., e.g., Frankfurt, 1971). So, the comparison here would not be between being an autonomous person and being a heteronomous person - a slave, a prisoner, or a person who is manipulated by presenting her only one-sided information, for example -, but between being an autonomous person and not being a person at all. Consequently, these kinds of imaginary cases do not demonstrate that we would rather be less happy autonomous persons than more happy heteronomous persons. In other words, they cannot show that we put intrinsic value on our autonomy.

\section{The value of making our own choices}

The main argument for the view that the value of patients' autonomy is not exhausted by its instrumental value in promoting their wellbeing is of the following kind. Proponents of this view refer to the value that making our own choices has for us and maintain that, at least in the case of significant decisions about our lives, making our own choices is so valuable for us that we are not willing to let other people to choose for us even if we are convinced that they could make better choices than we can. Some philosophers who accept this view do not present any reasons to explain this unwillingness. Others maintain that in making our own choices we are being agents, we are using our rational capacities, we are controlling our own lives, we are having a sense of living our own lives, we are creating and forming ourselves, we are giving our lives meaning, purpose, and distinctive 
uniqueness, and/or we are expressing ourselves. (see Glover, 1977, p. 81; Brock and Buchanan, 1990, pp. 38-39; Harris, 2003, p. 11) Below I will refer to this argument as the argument for autonomy.

Our unwillingness to delegate our important choices to others

Proponents of the argument for autonomy do not discuss exactly how the cases of our wanting to make our own choices when we believe that others could choose better should be defined. Someone might, for example, argue that, the rare cases of genuine self-sacrifice aside, making one's own choices always enhances one's wellbeing so that there might not be cases where a person could decide to make her own choices at the expense of her wellbeing. I will now put this problem aside and, for the sake of argument, assume that making one's own decisions would not enhance one's wellbeing more than letting others choose for one.

Imagine then the case of a patient who is considering whether or not he should undergo a complicated medical operation. Let us assume that, although the patient qualifies as autonomous, he is not as capable of taking in all the medical information relevant to assessing the risks and benefits of the operation as his physician is and that, as his physician is more mature and experienced in life than he is, the physician is more able to determine what would best serve the patient's good that the patient himself is. The patient is aware of these differences between him and his physician, but still wants to make his own decision about the operation. I assume that this would qualify as the kind of case that the argument for autonomy refers to. Someone might however argue that the patient's condition has shattered his existence so that he is not able to make autonomous decisions after all. To sidestep the complications presented by this type of criticism, I will for now concentrate on the case of healthy persons, in which this kind of problem does not arise when other things are assumed to be equal. I however take it that there can be autonomous patients and think that the discussion below is relevant to the questions arising within the medical sphere too.

I assume that the choices of whom to marry and what line of job to pursue qualify as the kind of important choices that the argument for autonomy refers to. Consider then the hypothetical case of person A who is faced with the option of delegating her choices of whom to marry and what line of job to pursue to experts. Let us assume that that studies show a significantly higher level of satisfaction among marriages and jobs chosen by experts than among those chosen by the individuals themselves, and that $\mathrm{A}$ is aware of this. A has had many relationships, but to her great regret she has not been able to find a suitable partner for marriage. Her situation with career is similar to her predicament with marriage. She has experimented with many different kinds of jobs, but is quite frustrated because she has not found anything that would feel at all right for her.

A is thus in a situation where she has good reason to believe that others could make better choices for her than she herself can. Is it plausible that $\mathrm{A}$, as a reasonable and autonomous person, would not be willing to delegate her choices of who to marry and what line of job to pursue to experts? Because A very much wants to get a satisfying career and find a suitable partner for marriage, it seems plausible that, rather than not being willing to delegate her decisions to experts, she would welcome the possibility to do that. By letting experts choose for her, A could finally get her life to go the way she wants it to go. A could, I think, be reluctant to renounce these choices to experts only if she were not really interested in finding a suitable partner and a good career.

Would paying attention to the reasons that proponents of the argument for autonomy present to explain our alleged unwillingness to let others choose for us make that argument more plausible? As was said above, when they explain it, proponents of the argument for autonomy explain this reluctance by saying that in making our own choices we are being agents, we are using our rational capacities, we are controlling our own lives, we are having a sense of living our own lives, we are creating and forming ourselves, we are giving our lives meaning, purpose, and distinctive uniqueness, and/or we are expressing ourselves.

Referring to these reasons does not seem to be helpful for the proponents of the argument for autonomy. To mention few of the most conspicuous problems, it seems not at all clear that we (should) want our lives to be unique - if indeed a coherent sense can be given to the notion of a person's life being unique, ${ }^{14}$ - a heteronomous person can have a sense of living her own life, and exercising one's rational capacities does not presuppose autonomy in the sense relevant here. For exercising one's rational capacities is a mental activity that does not require making real choices among options that are actually available for one and, thus, persons with 
no free choice, such as slaves, can exercise their rational capacities. Furthermore, adopting the values that the proponents of the argument for autonomy present to explain our alleged reluctance towards letting others choose for us does not commit us to accepting that there is reason to allow persons to make their own choices when they consider others more capable of getting good results for them, since each of these values can be pursued when persons are better at making choices than others, or equally good with them. Let us however now put these problems aside and, with these alleged reasons for wanting to make our own choices in mind, consider A's life after she decided not to let experts make her choices of whom to marry and what line of job to pursue.

A continued to seek a partner, but could not find a suitable one. A couple of times she thought she had found her perfect match, and she even married twice, but her marriages ended in divorces. She became even more frustrated with her work, which currently is nothing but a drag for her. Due to marital and work problems, she has become depressive and considers that only alcohol can console her, etc. However, what has happened to A follows from her own autonomous choices. She has been an agent and used her rational capacities to create herself and to control her life, she has had a sense of living her own life, and she has defined her life's meaning and purpose in her own assumedly unique way. A then complains to B that she has ruined her life and that she is miserable. $\mathrm{B}$ asks her: "Can you really find nothing of value in your life?" After considering B's question for a while, A answers: "It is true that I have completely messed up my life, but there is one thing that I can be proud of, one thing that definitely has value for me: it is me who has brought about this disaster!" If autonomy would have value for us independently of its contribution to our wellbeing, A's answer could be considered as a serious and reasonable one. However, rather than as a serious answer to the question presented to her, A's reply cannot be taken as anything else than an ironic self-pitying remark made in order to ridicule both herself and the person presenting the question. In other words, although $\mathrm{A}$ is, and has been, autonomous, her autonomy as such has no value for her. ${ }^{15}$

A proponent of the argument for autonomy might insist that A's case does not show that we do not value our autonomy irrespective of its effects on our wellbeing, but merely that we value other things in addition to our autonomy. Although A does value her autonomy, this objection could proceed, she values the wellbeing that getting a satisfying job and a good marriage assumedly could have brought even more. However, the argument for autonomy claims that we put so much value on making our own choices in important matters of our lives that we are not willing to give it up even if we were convinced that others could make better choices for us than we can. If this were true, A should not be more interested in her wellbeing than she is in her autonomy.

It might also be suggested that A's life still went better than it would have gone without autonomy; her life would have been even worse if it had been ruined by someone else than A herself. However, I would argue that bad choices are the worse for us the more they are of our own making. If, for example, a person commits what she considers to be a terrible crime autonomously, why should she consider it to be positively valuable for her that it was she who committed the crime? If committing the crime requires some special skills that the person has to a rare degree, she can be proud of having these skills, but it would be intuitively implausible to maintain that her using these skills in a way that she considers to be bad could have intrinsic positive value for her.

Assuming that experts could have chosen a good job and a suitable partner for A, those accepting the argument for autonomy might still claim that in A's case the imbalance between autonomy and wellbeing is too big, and that if the increase in wellbeing that A could have gained by renouncing her choices to the experts had been smaller, A would not have had reason to be willing to let the experts make her choices for her. But what would be an acceptable balance between autonomy and wellbeing for proponents of the argument for autonomy? Glover (1977, p. 81) says that if we were hideously tortured or going mad, we might be willing to sacrifice our autonomy to avoid these disasters. But referring to that kind of balance between autonomy and wellbeing would not support the argument for autonomy, since even A was not, nor is, hideously tortured and there is no serious threat of her going mad.

To get a case where the imbalance between autonomy and wellbeing cannot be too big for proponents of the argument for autonomy, let us consider the case where renouncing one's choices to others could bring one only a small gain in wellbeing. Let us assume that $\mathrm{B}$ has found a partner that she likes very much and that she is pursuing a career that brings her great satisfaction. She is quite happy with both her fiancé and her job, 
but still thinks that there are some things that could be even better. $\mathrm{B}$ is then offered the possibility to delegate her decisions of whom to marry and what line of job to pursue to experts, and she is aware that studies show a higher level of satisfaction among marriages and jobs chosen by experts than among those chosen by the individuals themselves. Should B, as a reasonable and autonomous person, be reluctant towards delegating her decisions to experts?

I think that B could be willing to let experts make her marriage and career choices. And even if she were not, this could not show that B values her autonomy irrespective of its effects on her wellbeing. It is plausible that B is emotionally attached to both her fiancé and her job and is therefore not willing to let go of them even though she believes that the experts could be a little bit better in choosing a partner and a job for her than she herself is. ${ }^{16}$ And although the studies show a higher level of satisfaction among marriages and jobs chosen by experts than among those chosen by individuals themselves, B may still find it doubtful that in her case experts really could succeed better than she herself. She is after all a highly competent person, and probably knows herself better than the experts. When B considers these things, she may think that, since she is faring sufficiently well already, in her case it does not pay to resort to any outside help. Her reluctance towards letting others to make her choices would thus ultimately be based on her valuing her wellbeing, not on her seeing her autonomy as valuable irrespective of its role in promoting her wellbeing.

It could be claimed that although the reason for our unwillingness to let others make our choices can sometimes be that we distrust others' ability to make better choices than we can, etc., there still are cases where this reluctance is based on our putting intrinsic value on our autonomy. But what reason does one have to accept this? I am unwilling to let others make my important life choices for me. But when I consider the possibility of letting others choose for me and find myself being reluctant towards doing that, I do not think about autonomy, agency, self-creation, expressing myself, etc., at least not irrespective of their possible role in promoting my wellbeing. Because I think there is great variation in what is good and bad for individual persons and believe that determining what would promote a person's wellbeing requires, among other things, a lot of specific knowledge about that person, I simply do not trust that others really could make choices that would be better for me than the ones that I can make, and my reluctance towards letting others choose for me is based on that. In addition to those discussed above, the argument for autonomy confronts still other problems. Below I turn to those difficulties.

\section{Delegating our choices to others and autonomy}

Proponents of the argument for autonomy thus aim to demonstrate that autonomy has intrinsic value for us by drawing attention to the alleged fact that we are not willing to delegate our important choices to other people even if we believe that they can make better choices than we can. A problem with this line of thinking is that letting others to make our important choices for us need not be incompatible with our being autonomous. If the person delegating her choices to others is autonomous to begin with and nobody manipulates or tricks her into renouncing her choices, coerces her, etc., in the understanding of the nature of individual autonomy now adopted, she remains autonomous after letting others make her important choices for her. Indeed, if others are more capable of getting the kind of results that the person wants, the person who lets others make her choices for her can thereby become even more autonomous than she were to begin with. This is because, as a consequence of letting others make her important choices for her, her life goes more in the way that she wants than it would have gone if she had made her choices by herself. Although the person resorts to other people's help, she does this autonomously and remains as a self-governing agent. At least for those accepting the procedural conception of autonomy, letting others make choices for one can thus be one autonomous decision among others. But if letting others choose for one does not compromise one's autonomy, arguing that we would not be willing to let others make our choices for us even if we believed them to be able to make better choices than we cannot demonstrate that we put intrinsic value on our autonomy.

A proponent of the argument for autonomy might object that we should see autonomy as a property of decisions and choices and that if a person lets others make her choices for her, she cannot be autonomous anymore. Let us, for the sake of argument, assume that autonomy is not primarily a property of persons, but a characteristic of the decisions and choices that persons make. However, when, for example, a patient autonomously decides to undergo a complicated 
surgery, we can reasonably consider her as autonomous with respect to that surgery even though she does not autonomously choose each action performed during the operation. Similarly, an autonomous person remains autonomous after letting others choose a job and a partner for her. If it is objected that the patient who gives her autonomous consent to undergo the surgery assesses each of the actions that will be performed during the operation beforehand and gives her advanced consent to them, it can be responded that this is possible in the case of the person who delegates her career and marriage choices to others too.

A critic might still insist that, even if her life would go more in the way that she wants it to go after she renounces her choices to others, the person who lets others choose for her is heteronomous with respect to making the particular choices that others then make on her behalf. As the person does not make these choices herself, this possible objection could proceed, she is not in control of them anymore. There are two points I would like to make concerning this possible criticism. First, the notion of 'control' can be understood in different ways. But at least when the person is able to withdraw her consent to letting others choose for her, it is intuitively plausible to accept that, in the sense relevant here, she has control over the choices that others make on her behalf. And in medicine, with the exception of patients like those who are under the influence of heavy anaesthetic, a patient who has given her informed consent to undergo a treatment is usually able to withdraw this consent if that is what she wants to do. Second, contrary to what this criticism presupposes, we should not accept that a person can be in the relevant sense in control of choices, decisions, and actions only if she performs them by herself. Accepting that a person can be autonomous with respect to choices, decisions, and actions only if she controls them in the sense that she performs them by herself has the counterintuitive implication that patients can remain autonomous only if they treat themselves without any resort to outside help. ${ }^{17}$ Consequently, I take it that this criticism should not be accepted.

Its explanation of our alleged unwillingness to let others make our choices for us results in a still further problem for the argument for autonomy. On the basis of my own case, I would argue that a person who considers the possibility of letting others choose for him and finds himself being reluctant towards doing that need not think about autonomy, self-creation, expressing herself, giving his life unique meaning, etc., at least not independently of their possible role in enhancing the person's wellbeing. If it is required that these things are an autonomous person's reasons for not letting others choose for her, it seems that the procedural conception of autonomy is being left behind. Although making such a requirement would not result in presenting substantive ends for autonomous persons so that one would then maintain, for example, that wanting to be a subservient housewife or requesting for euthanasia can never be autonomous, it would however rule out some substantive views on other than purely procedural grounds. To maintain that an autonomous person wants to express herself, that an autonomous person wants to have a distinctive and unique life, etc. is to say, for example, that a person who does not want to stand out from others and prefers to live a quiet and ordinary life that is not expressive of an unique self, etc. is heteronomous. And, for obvious reasons, saying that this kind of person is heteronomous cannot be based on purely procedural points of departure. Thus, the view maintaining that an autonomous person does not want to let others choose for her because she wants to express herself, because she wants to have an unique life, etc. is incompatible with the procedural conception of autonomy that the proponents of the argument for autonomy accept.

It might be objected that at least agency and having control over one's life are the kind of reasons that are compatible with accepting a procedural conception of autonomy. However, in voluntary euthanasia and physician-assisted suicide, for example, one ceases to be an agent and loses control over one's life. If a conception of autonomy rules out these procedures to begin with, it cannot be a purely procedural conception of autonomy. In other words, if the argument for autonomy presupposes that one must want to be an agent and to have control over one's life so that one cannot want to request for euthanasia or to desire to make a suicide, then its conception of autonomy is not procedural.

To recapitulate, the argument for autonomy consists of maintaining that we would not be willing to let others make our important choices for us even if we believed that they could make better choices than we can. This is taken to demonstrate that we put intrinsic value on our autonomy. And some of the proponents of the argument for autonomy maintain that our alleged unwillingness to let others choose for us can be explained by referring to the fact that in making 
our own choices we are being agents, we are using our rational capacities, we are controlling our own lives, we are having a sense of living our own lives, we are creating and forming ourselves, we are giving our lives meaning, purpose, and distinctive uniqueness, and/or we are expressing ourselves. Above I argued for several points against the argument for autonomy. First, contrary to what the argument for autonomy presupposes, it plausible that autonomous and reasonable persons are willing to let others choose for them if they believe that others can make better choices than they themselves can. Second, many of the reasons that proponents of the argument for autonomy present for our alleged reluctance towards letting others choose for us do not presuppose autonomy. Third, accepting the reasons for our alleged unwillingness to let others choose for us that the proponents of the argument for us that the proponents of the argument for autonomy refer to does not commit one to accepting that persons should be allowed to make their own choices when other could choose better than them, because these reasons can be pursued when others are equally good, or worse, at making choices. Fourth, even if a person would not be willing to let others choose for her, this would not demonstrate that she puts intrinsic value on her autonomy, as this unwillingness has other, and more plausible, explanations. Fifth, contrary to what the argument for autonomy presupposes, if one's decision to let others choose for one is autonomous, it does not compromise one's autonomy. Sixth, the reasons that proponents of the argument for autonomy present for our alleged reluctance towards letting others choose for us are incompatible with the procedural conception of autonomy that they accept. ${ }^{18}$ I conclude that the argument for autonomy is not able to show that autonomy has intrinsic value for us.

\section{Possible objections considered}

Above I have already addressed some minor objections, but in this section will concentrate on more fundamental criticisms of the main argument of this paper.

\section{Ultimate values cannot be justified?}

It might be objected that it is not reasonable to insist that proponents of autonomy should be able to justify the view that patients' autonomy has intrinsic value, since autonomy is a fundamental value and fundamental values cannot be justified. There are two points I would like to make regarding this possible criticism. First, although disagreements about fundamental values have most probably existed trough human history, and many of them have survived two millennia of philosophical analysis, the question of whether or not fundamental values can be justified would seem to be an open one. At least, metaethical discussion concerning questions about the ontological status of values and our ability to have knowledge about what is valuable and what is not is still going on, and many philosophers are optimistic about the possibility of justifying even fundamental values (see, e.g., Smith, 2002; Watkins and Jolley, 2002; Rachels, 2003).

Second, even if it were the case that fundamental values cannot be given any strong justification, requiring at least some plausible reasons for considering autonomy to have intrinsic value would seem to be reasonable. For even if we accepted that fundamental values cannot be justified in any strong sense, we have some criteria for what we allow as fundamental values, and it can be asked whether or not autonomy fulfils that criteria. Even if a person sincerely declares that her ultimate end in life is to, say, eat pebbles, most of us would, I think, be hesitant towards accepting eating pebbles as a fundamental value. Instead of immediately taking it that eating pebbles can be a fundamental value for an autonomous person, we would at least want to be assured that the person accepting it as a fundamental value really is autonomous. We thus have some criteria of what qualifies as a fundamental value, and of all candidates for such a value it can be asked whether or not they fulfil that criteria and why.

\section{Who has the burden of proof?}

It might be objected that even though we have some criteria for what can and what cannot be a fundamental value for autonomous persons, it is quite clear that autonomy satisfies that criteria. Instead of requiring that autonomy's value should be justified, this possible criticism could proceed, it is the view that rejects autonomy's having intrinsic value for us that is in need of justification. Since autonomy is so widely valued, it is clear that the burden of proof here is on the side that wants to reject the view that autonomy has intrinsic value.

However, although autonomy is a central value in Western medicine and medical ethics, as I said above, exactly what role it should have in medicine 
is not clear. There is no consensus that autonomy should be valued irrespective of its role in promoting patients' wellbeing, and even those bioethicists who consider there to be cases where autonomy should override wellbeing disagree on what these cases are. Consequently, it is plausible to take it that the burden of proof here is on the proponents of the view that patients' autonomy should be valued even if it were not conducive to patients' wellbeing.

\section{Are justifications unnecessary in self-regarding matters?}

It could also be objected that even though the view that patients' autonomy has intrinsic value is controversial, we are now discussing patients' self-regarding matters. And, this possible objection could proceed, respecting persons as persons requires that in their self-regarding matters autonomous persons are allowed to do whatever they want, irrespective of whether or not their actions can be given any justification.

For the sake of argument, I will now assume that a plausible distinction between self-regarding and other-regarding matters can be made, and that the patients' actions now in question fall into the selfregarding category. As I have explained above, proponents of autonomy maintain that we value autonomy so much that we want to make our own decisions even if we know them to be bad ones, or at least not as good as they could be. ${ }^{19}$ Thus the question here is about a case where the patient who is not willing to let others choose for her even though she believes others to be able to make better choices wants something that has value for her. Then, even though there were no need for the patient to justify her choices to others, it can be asked whether or not she is able to justify them to herself.

If a person who wants something that has value for her cannot explain to herself how what she is contemplating of doing could bring her something of value, she is being irrational. Although the procedural conception of autonomy allows persons to completely disregard themselves if that is what they autonomously want, it excludes this kind of irrationality. The kind of minimal instrumental rationality now at issue is arguably required by any plausible conception of individual autonomy. So, either the person who is not willing to let others make choices for her when she is convinced that others could make better choices than she herself can is heteronomous or she sees something in making her own choices that overrides the loss of wellbeing she is willing to undergo by not letting others make her choices for her. But what could this something be?

Above I argued that the arguments bioethicists have presented for the view that patients' autonomy has value over and beyond its value in promoting the patients' wellbeing are not plausible. If these arguments are not able to show that procedural autonomy has intrinsic value for us, nor to demonstrate that we can hold autonomy as a fundamental intrinsic value, how can the patient now in question justify to herself that making her own choices would be valuable for her irrespective of their consequences to her wellbeing? If she is unable to explain that, she does not qualify as an autonomous agent and, consequently, her case is irrelevant to the present discussion as this debate concerns the case of autonomous persons. Thus, even if we allowed autonomous patients to do what they want in their self-regarding matters, and the kind of medical matters now at issue were purely self-regarding, it seems that autonomous patients could not be willing to make their own choices when they are convinced that others could make better choices for them. ${ }^{20}$

\section{Conclusion}

In this article I have examined the arguments that bioethicists have presented for the view that patients' autonomy has value over and beyond its value in promoting the patients' wellbeing. I concentrated on the procedural conception of autonomy commonly accepted in medical ethics, and maintained that the arguments to the effect that patients' autonomy has intrinsic value are not plausible. To the extent that this is acceptable, in cases where autonomous patients want to make choices that they admit to be bad for them, it is more plausible to take them to be speaking about badness in inverted commas than to accept that there is intrinsic value in autonomy that could overweigh the harm or loss of wellbeing that they would suffer as a result of their making bad choices. In other words, in the light of the main argument of this article, it is plausible that ultimately the question with these kind of cases is about competing conceptions about what is good and bad for patients, not about the value of autonomy. As long as medical ethics refers to the procedural conception of autonomy and more plausible arguments for the view that patients' autonomy has intrinsic value are not presented, 
patients' autonomy should be taken to have only instrumental value in medicine. ${ }^{21}$

\section{Notes}

1. Beauchamp and Childress (2001, pp. 185-187) also maintain that "under some conditions a narrow range of strongly paternalistic acts is justified." This means that in the majority of cases autonomy can override wellbeing. And Beauchamp and Childress (2001, p. 186) are inclined to accept that even when paternalism is justified, the paternalistic action should not "substantially restrict autonomy."

2. See, e.g., Beauchamp and Childress (2001, pp. 185187) and Glover (1977, p. 75 cf. p. 81). All philosophers accepting the view that patients should be allowed to make choices that these patients admit to be bad, or at least not as good as they could be, do not specify whether they think there to be some cases where autonomous patients' self-regarding actions can be restricted.

3. Harris would seem to hold this kind of view. Harris (2003, p. 11) writes as follows: "Concern for welfare ceases to be legitimate at the point at which, so far from being productive of autonomy, so far from enabling the individual to create her own life, it operates to frustrate the individual's own attempts to create her own life herself."

4. Alternatively, it can be taken that autonomy is a property of decisions and choices (see, e.g., Beauchamp and Childress (2001, p. 58)). To the extent that it is necessary from the point of view of the main argument of this paper, I will return to this distinction between autonomy as a property of decisions and choices and autonomy as a property of persons below.

5. For a defense of a partly substantive conception of autonomy see Oshana (1998).

6. The views that are referred to as Kantian can be even radically dissimilar to each other, see, e.g., Secker (1999) for discussion.

7. The most common criticism of the procedural theories of individual autonomy is that in stressing the value of a person's own independent decisions, they are incompatible with such communitarian virtues as empathy, loyalty, and care and respect for tradition, ritual, and the counsel of others. For a plausible reply to this criticism see Oshana (2001) (whose own theory of autonomy contains substantive elements) and also, e.g., Gylling (2004). Oshana argues that this communitarian criticism of individual autonomy is an objection to a straw man, while Gylling warns us about uncritical acceptance of traditional values. Gylling writes, "If moral integrity is to have any meaning, ethically attentive individuals should critically assess the merits and dismerits of predominant credos. Conservative and unquestioning acceptance of traditional values may turn moral life into a mechanical - even if bona fide - acceptance of either ruthless and inhuman morals or a hollow etiquette, a code of honor." Gylling (2004, p. 46).

8. In addition to the philosophers who maintain that patients' autonomy has value beyond its instrumental value in promoting the patients' wellbeing mentioned above see, e.g., Mappes and Zembaty (1991), Matthews (2000), Secker (1999), and Young (1998). For discussion of Kant's and Kantian concepts of autonomy in medicine and some persuasive arguments against the view that medical ethics should refer to these kinds of conceptions to autonomy, see, e.g., Matthews (2000), Secker (1999), and Takala and Häyry (2000).

9. That I will not argue for the possibility of intrinsic value in general should not beg the question here, since I will be arguing against the view that patients' autonomy has intrinsic value.

10. It could be objected that if the proponents of the view that patients' autonomy has value for the patients over and beyond its value in promoting their wellbeing do not specify how they perceive the value of autonomy, it is implausible to maintain that they consider autonomy to have intrinsic value for the patients. However, at least when other things are being equal, the most plausible interpretation of the view that patients' autonomy has value for them over and beyond its instrumental value in enhancing their wellbeing is that autonomy has intrinsic, and not economic, aesthetic, etc., value for them.

11. Sometimes defenses of personal autonomy refer to Kant and Mill (see, e.g., Beauchamp and Childress (2001; pp. 63-64, cf. p. 351)). But since Kant deems the choices a person makes on the basis of her own desires, inclinations, and wishes as heteronomous, Kant is not directly relevant to arguing for the kind of autonomy that has a prominent role in contemporary medicine. For detailed arguments to this effect see, e.g., Matthews (2000) and Secker (1999). And it is unclear to what extent Mill considered autonomy to have intrinsic value, and whether or not putting intrinsic value on autonomy is consistent with his utilitarianism. Be that as it may, Mill did maintain that making our own choices exercises our rational capacities and helps us to build a character (Mill, 1985, pp. 122-124), and these reasons for putting intrinsic value on autonomy are discussed below.

12. Gillon (2003, p. 310) says that autonomy is morally precious because it makes morality possible. It is not altogether clear how this should be taken. If it means that autonomy should be valued because it gives persons the possibility to perform morally good actions, it can be responded that these goods are overweighed by the grave moral wrongs that autonomy makes possible to commit. Procedural autonomy in itself is neutral between morally good and bad actions and can be used in good and bad ways (see, e.g., Dworkin (1988)). And even if we concentrated on the morally good things that autonomy makes possible, it can be asked are these things better than the kinds of goods 
that do not involve autonomy? In other words, this line of thinking would just take us back to the question of does autonomy have intrinsic value. Furthermore, we can reasonably consider persons as morally culpable for actions that they did not perform autonomously (see, e.g., Oshana (2002)). For example, consider the case in which a heavily drunk person hits another person with her car with the consequence that the latter person dies. It is intuitively plausible to consider the drunk as morally culpable for the other person's death even if she did not autonomously choose to kill him. And finally, the view that autonomy is morally precious because it makes morality possible would seem to make the value of autonomy derivative from the value of morality.

13. Glover (1977, p. 75) also says that if someone wants to start taking heroin, he thinks it right to stop the person, because he gives less weight to autonomy in this matter than to sparing the person "the appalling suffering involved in the slow death of a heroin addict." Glover thus accepts that autonomy can be restricted only if there is threat of extremely severe harm to wellbeing.

14. Our lives can of course be unique in the trivial sense that no one else was born from the same parents at exactly the same time, but this would not seem to support the argument for autonomy.

15. There admittedly are persons who declare that even though the choices they have made were bad, were they given the possibility to go back in time and start all over again, they would make exactly the same choices as they did the first time around. But, as such, their cases do not imply that autonomous persons would really want to repeat choices that they consider to be altogether bad. There are advantages in being able to retain a positive image of oneself in the eyes of oneself and others, and to the extent that these declarations are not these persons' attempts to present themselves as more competent agents than they have been, it is plausible, I think, that they consider that nobody could have been able to help them and that as a result of making their mistakes they have learnt valuable lessons and consequently know how to avoid similar mistakes in the future.

16. I do not mean to confuse considering the thoughtexperiment with actually choosing whether or not let others choose for one. However, if the former is to be plausible and effective, it must be quite reminiscent of the latter, and hence follows this problem.

17. Relevant to this point is, e.g., May's (2005) response to the criticisms of autonomy maintaining that the conception of self that autonomy usually presupposes cuts the self off from others and therefore cannot account for the significance of the social dimensions of identity, relationships, etc. Instead of considering an autonomous agent to be an island, May maintains that an autonomous person should be seen as a helmsman who steers her own life and may resort to others' assistance in doing so.
18. It could be maintained that the problems pertaining to the reasons that allegedly make us reluctant towards letting others choose for us are problems only to those proponents of the argument for autonomy who refer to them and that therefore those philosophers accepting the argument for autonomy who do not speak about these reasons can still be considered to have a plausible view about the value of autonomy. However, of the objections listed above, one, four, and five do apply to these philosophers' view and these criticisms are sufficient to show that the argument for autonomy that does not refer to the problematic reasons referred to above is not able to establish the view that autonomy has intrinsic value for us.

19. I now refer to making one's own choices only, but what I will say below applies, mutatis mutandis, to the case of the Brave New World argument as well.

20. It could be maintained that although autonomy does not have intrinsic value, it still is a necessary condition of everything that has value for us (see, e.g., Rachels and Ruddick (1989)) and, consequently, it should always be taken into account even if this were not the instrumentally best way to promote a patient's wellbeing. However, even if we accepted that autonomy conditions the value that things have for us, it seems that then bad choices would be the worse for us the more they were of our own making. In other words, even if we accepted that autonomy has this kind of conditional value, that a bad choice is made autonomously would not make that choice good for one.

21. I thank Juha Räikkä and two anonymous reviewers for helpful comments on an earlier version of this paper.

\section{References}

Beauchamp, T.L. and J.F. Childress: 2001, Principles of Biomedical Ethics (5th ed.). New York: Oxford University Press.

Buchanan, A.E. and D.W. Brock: 1990, Deciding for Others: The Ethics of Surrogate Decision Making. New York: Cambridge University Press.

Dworkin, G.: 1988, The Theory and Practice of Autonomy. New York: Cambridge University Press.

Frankfurt, H.: 1971, Freedom of the Will and the Concept of a Person, Journal of Philosophy 68(1), 829-839.

Gillon, R.: 2003, Ethics Needs Principles - Four Can Encompass the Rest - and Respect for Autonomy Should be "First Among Equals", Journal of Medical Ethics 29(5), 307-312.

Glover, J.: 1977, Causing Death and Saving Lives. Harmondsworth: Penguin Books.

Gylling, H.A.: 2004, Autonomy Revisited, Cambridge Quarterly of Healthcare Ethics 13, 41-46.

Harris, J.: 2003, Consent and End of Life Decisions, Journal of Medical Ethics 29(1), 10-15.

Mappes, T.A. and J.S. Zembaty: 1991, Biomedical Ethics. New York: McGraw-Hill, Inc.. 
Matthews, E.: 2000, Autonomy and the Psychiatric Patient, Journal of Applied Philosophy 17(1), 59-70.

May, T.: 2005, The Concept of Autonomy in Bioethics: An Unwarranted Fall from Grace, in: J.S. Taylor, (ed.), Personal Autonomy: New Essays on Personal Autonomy and Its Role in Contemporary Moral Philosophy. Cambridge University Press: New York, pp. 299-309.

Mill, J.S.: 1985, On Liberty. Harmondsworth: Penguin Books.

Oshana, M.A.L.: 2002, The Misguided Marriage of Responsibility and Autonomy, Journal of Ethics: An International Philosophical Review 6(3), 261-280.

Oshana, M.A.L.: 2001, The Autonomy Bogeyman, The Journal of Value Inquiry 35, 209-226.

Oshana, M.A.L.: 1998, Personal Autonomy and Society, Journal of Social Philosophy 29(1), 81-102.

Rachels, J. and W. Ruddick: 1989, Lives and Liberty, in: J. Christman, (ed.), The Inner Citadel: Essays on Individual Autonomy. Oxford University Press: New York, pp. 221-233.

Rachels, S.: 2003, A Defense of Two Optimistic Claims in Ethical Theory, Philosophical Studies 112, 1-30.
Secker, B.: 1999, The Appearance of Kant's Deontology in Contemporary Kantianism: Concepts of Patient Autonomy in Bioethics, Journal of Medicine and Philosophy 24(1), 43-66.

Sumner, L.W.: 1996, Welfare, Happiness, and Ethics. Oxford: Clarendon Press.

Smith, M.: 2002, Exploring the Implications of the Dispositional Theory of Value, Philosophical Issues 12, 329347.

Takala, T. and M. Häyry: 2000, Genetic Ignorance, Moral Obligations and Social Duties, Journal of Medicine and Philosophy 25(1), 107-113.

Watkins, M. and K.D. Jolley: 2002, Pollyanna Realism: Moral Perception and Moral Properties, Australasian Journal of Philosophy 80, 75-85.

Young, R.: 1998, Informed Consent and Patient Autonomy, in: H. Kuhse, and P. Singer (eds.), A Companion to Bioethics. Blackwell Publishers Inc.: Oxford, pp. 441-451. Zimmerman, M.J.: 2001, The Nature of Intrinsic Value. Lanham, MD: Rowman \& Littlefield. 